\title{
Thermodynamic feedback processes in a single-column sea-ice-ocean model
}

\author{
Marika M. Holland, Julie L. Schramm, Judith A. Curry \\ Department of Aerospace Engineering, CB 429, University of Colorado, Boulder, CO 80309, U.S.A.
}

\begin{abstract}
Due to large uncertainties in many of the parameters used to model sea ice, it is possible that models with significantly different physical processes can be tuned to obtain realistic present-day simulations. However, in studies of climate change, it is the response of the model to various perturbations that is important. This response can be significantly different in sea-ice models that include or exclude various physical feedback mechanisms. Because simplifications in sea-ice physics are necessary for general circulation model experiments, it is important to assess which physical processes are essential for the accurate determination of the sensitivity of the ice pack to climate perturbations. We have attempted to address these issues using a new coupled ice-thickness distributionocean mixed-layer model. The sensitivity of the model to surface heat-flux perturbations is examined and the importance of the ice-ocean and ice-albedo feedback mechanisms in determining this sensitivity is analyzed. We find that the ice-ocean and ice-albedo feedback processes are not mutually exclusive, and that they both significantly alter the model response to surface heat flux perturbations.
\end{abstract}

\section{INTRODUCTION}

Sea ice is important for climate in that it modifies oceanatmosphere interactions, and has a large effect on the surface-energy and momentum budgets in the polar regions. Doubled $\mathrm{CO}_{2}$ general circulation model (GCM) studies have shown a large amplified warming response in high latitudes (e.g. Houghton and others, 1990). This is associated with a significant retreat of the sea-ice cover. Feedbacks associated with the sea-ice system are largely responsible for the amplified high-latitude warming. Rind and others (1995) estimate that sea-ice effects are responsible for $37 \%$ of the global surface air-temperature sensitivity in a GCM $\mathrm{CO}_{2}$ doubling study. In a study of sea-ice extent and surface temperature data in high latitudes for the last 40 years, it was found that the summertime sea ice in the Arctic is becoming less extensive (Chapman and Walsh, 1993). However, large surface air-temperature warming trends, such as those predicted by increasing $\mathrm{CO}_{2} \mathrm{GCM}$ studies, are not present during the same time period (Kahl and others, 1993). Uncertainties remain in the response of the modeled polar climate to climate change, largely due to the inadequate parameterization of physical processes of the oceansea-ice atmosphere system.

One of the most important of the high-latitude climatefeedback mechanisms is caused by changes in surface albedo. Since the albedo of ice and snow is substantially larger than that of open water or bare land, changes in the snow and ice cover in polar regions significantly affect the surface albedo. As surface temperatures rise, the sea-ice extent in the Arctic decreases and more open water appears. This decreases the surface albedo and allows more solar radiation to be absorbed by the Earth, causing temperatures to increase further. Conversely, decreases in the surface temperature lead to increased surface albedo that causes the cooling to be reinforced. Recently, Curry and others (1995) have shown that the sea-ice albedo feedback can operate even in perennial multi-year pack ice due to internal processes occurring within the pack ice. These processes include the duration of the snow cover, the thickness and distribution of different ice types, the amount of open water that occurs in the pack ice, and the surface melt-pond characteristics. Currently, the strength of the sea-ice albedo feedback mechanism is uncertain. Substantial differences exist between estimates of the ice-albedo feedback in different GCMs (e.g. Ingram and others, 1989).

It appears that feedbacks between the ice-thickness distribution and the ocean may also be an important factor for climate change studies. Ebert and Curry (1993) identify several positive ocean feedback mechanisms related to the penetration of solar energy through leads and thin ice and the amount of lateral ablation that occurs in leads. Negative feedbacks related to the ice-ocean interactions have also been identified. Using a coupled ice-ocean basin model, Weatherly (1996) showed that increased surface ablation caused by a surface-warming perturbation allows more fresh water to enter the ocean, stabilizing the water column and allowing less heat to be entrained from the deeper ocean. In the context of a GCM modeling study, Rind and others (1995) showed similar results for the Southern Ocean sea-ice cover.

Sea-ice growth and transport is affected by both dynamics and thermodynamics. A good understanding of these processes is essential if sea ice is to be modeled more accurately. In addition, feedbacks between the ice-thickness distribution, the ocean mixed layer, and the atmosphere play an important role in the stability of the ice pack. Seaice models frequently do not account for many of the internal processes in the ice pack, and their effects on the ice-ocean and ice-atmosphere interactions. Thus, many of 
these models may not respond realistically to perturbations of the system because they exclude important physical processes that contribute to climate-feedback mechanisms.

We attempt to address some of these issues with the use of a coupled ice-thickness distribution-ocean mixed-layer model. First, a brief description of the model is given. We then describe the model sensitivity to surface longwave heat-flux perturbations. In particular, the effects of feedback mechanisms involving the surface albedo and the ocean mixed layer are examined.

\section{MODEL DESCRIPTION}

The numerical model used in this study is a single-column representation of the coupled sea-ice ocean system. Since the basic model sea-ice thermodynamics is described in detail in Schramm and others (in press) and the ocean component and sea-ice ocean interactions are described in Holland and others (in press), only a brief description is given here. The sea-ice model component is an ice-thickness distribution model that allows for a specified number of level and ridged ice categories within the model domain. This allows us to represent the high spatial variability apparent in the observed sea ice. The different ice categories are described by a variety of properties and evolve thermodynamically, independently of one another. Different interfacial heat fluxes are computed for each ice category. A complex surface-albedo parameterization (Ebert and others, 1995) is used that considers four different spectral intervals and accounts for six different surface types, including dry snow, wet snow, bare first-year ice, bare multi-year ice, melt ponds, and open water.

In addition to thermodynamic processes, the sea-ice thickness distribution is affected by mechanical forcing. Divergent sea-ice motion causes sea ice to be exported from the model domain whereas convergent motion causes ice ridging to occur. Shearing of the ice pack causes both open water and pressure ridges to form. The parameterization of these processes has been modified from Schramm and others (in press), and is achieved by using a "redistributor" function that reorganizes the ice in the model domain based on the dynamic forcing. The function used here is consistent with a plastic rheology, and follows the formulation of Thorndike and others (1975), Rothrock (1975) and Hibler (1980). In the ridging process only the thinnest 0.10 fraction of the model domain is allowed to participate, and it is assumed that the ridged ice is 15 times the thickness of the ice that formed the ridges (Maykut, 1982). Strain-rate data from Arctic Ice Dynamics Joint Experiment (AIDJEX) (Colony, 1978) are used to drive the model dynamics.

The sea-ice model is coupled to a bulk ocean mixedlayer model (Gaspar, 1988) that has uniform temperature and salinity within the mixed layer. The mixed-layer properties change due to the exchange of heat and fresh water with the atmosphere, or sea ice above and the deeper ocean below. The total heat flux at the surface of the mixed layer is determined by the turbulent exchange at the ice-ocean interface, the penetration of solar radiation through ice and leads, and the other surface radiative fluxes at the lead surface. The flux of fresh water at the mixed-layer surface is determined by the amount of ablation or accretion at the ice base, meltwater runoff from the ice surface, brine drainage as the ice ages, fresh-water inflow (representing river runoff), and precipitation and evaporation through leads. Heat and salt are also exchanged with the ocean beneath the mixed layer through entrainment as the mixed layer deepens, and through diffusion across the mixed-layer base.

An annually averaged ice thickness of $3.05 \mathrm{~m}$ is obtained in the baseline simulation. This is consistent with the generally accepted average Arctic sea-ice thickness of $3 \mathrm{~m}$ (e.g. Bourke and Garrett, 1987). The annually averaged areal percentage of open water, first-year ice, multi-year ice and ridged ice are $3 \%, 17 \%, 32 \%$ and $48 \%$, respectively. As a result of the sparse number of observations available, it is difficult to determine the accuracy of the ice-thickness distribution that is obtained. The penetration of solar radiation and the subsequent elevation of mixed-layer temperature above the freezing point are in general agreement with in situ data and model results from AIDJEX (Maykut, 1982; Maykut and McPhee, 1995). In addition, mixed-layer salinity, temperature and depth show reasonable agreement with AIDJEX data.

\section{SENSITIVITY EXPERIMENTS}

The sensitivity of the model to surface heat flux perturbations is examined by applying a fixed perturbation to the downwelling longwave (LW) forcing at each time-step. A baseline simulation is obtained by running the full model to an "equilibrium" state with no perturbations to the forcing. Four different versions of the model are run to equilibrium with the perturbed forcing in order to examine the influence of changes in the surface albedo and the ocean mixed-layer properties on the model behavior. They include (1) a control case with an interactive albedo and ocean mixed layer, (2) a case in which the albedo annual cycle is fixed at the baseline value, (3) a case in which the annual cycle of ocean mixed-layer properties remains at the baseline values, and (4) a case in which both the albedo and ocean mixed-layer properties remain at the baseline values. We examine the response of all four versions of the model to both warming and cooling perturbations and focus on the response of the sea-ice thickness.

In particular, we apply perturbations up to $25 \mathrm{~W} \mathrm{~m}^{-2}$ in magnitude. The direct radiative forcing associated with a $2 \times \mathrm{CO}_{2}$ scenario is approximately $4 \mathrm{~W} \mathrm{~m}^{-2}$ (e.g. Ramanathan and others, 1989). Significant changes in surface radiative forcing are also caused by variations in cloud cover and properties. Curry and others (1993) found that the annually averaged downwelling radiative surface flux varies by approximately $30 \mathrm{~W} \mathrm{~m}^{-2}$ as cloud fraction increases from $0 \%$ to $100 \%$. Thus, the largest perturbations that are applied in this study $\left(25 \mathrm{~W} \mathrm{~m}^{-2}\right)$ represent extreme changes in the climate system.

In order to compare the importance of the feedback mechanisms, we examine the system gain of the ice-thickness response. The gain is equal to the fraction of the change in ice thickness that is caused by a particular feedback process. For example, if the gain equals zero, no portion of the change in ice thickness is due to the feedback mechanism, and a perturbation experiment will obtain the same ice thickness regardless of whether it includes the feedback. System gain is computed as (i.e. Hansen and others, 1984):

$$
g=\frac{\Delta h_{\text {feedbacks }}}{\Delta h}
$$

where $\Delta h$ is the total ice-thickness change when all feed- 
backs are operative and $\Delta h_{\text {feedbacks }}$ is the net feedback portion of the ice-thickness change. We obtain $\Delta h_{\text {feedbacks }}$ as:

$$
\Delta h_{\text {feedbacks }}=\Delta h-\Delta h_{0}
$$

where $\Delta h_{0}$ represents the change in ice thickness when the feedback mechanism is inoperative. Thus, we obtain a measure of the importance of the feedback mechanism by comparing a perturbation experiment that includes the feedback to a perturbation experiment that excludes the feedback. This allows us to assess how much of the change in ice thickness is due to the presence of a particular feedback mechanism, as opposed to the direct effects of the LW warming perturbation and the effects of other feedback processes that are active. If the feedback mechanisms are independent, then the gain of the combined feedback is equal to the sum of the gains of the individual feedbacks. System gains are computed and compared for the albedo, ocean and combined albedo- ${ }^{-}$cean feedbacks.

\section{Warming perturbations}

The response of the annual cycles of ice thickness, surface albedo, and basal heat flux to a $10 \mathrm{~W} \mathrm{~m}^{-2} \mathrm{LW}$ warming and cooling perturbation is presented in Figure 1. The model response to cooling perturbations is discussed in the next section. Clearly, in the warming case the ice thickness has been reduced by a substantial amount (approximately $1.1 \mathrm{~m}$ in the annual average) (Fig. la). This is largely due to feedback processes that occur during the summer months, even though the perturbation is applied year-round. The warming perturbation causes a longer melt season and more surface ablation to occur. This results in a lower summertime surface albedo (Fig. 1b) that allows more solar radiation to be absorbed by the sea-ice system. This, in addition to the increased net LW warming, causes an increase in the annual average surface-meltwater runoff of $0.37 \mathrm{~m}$. In addition, the presence of larger summertime lead fractions and thinner ice allows more solar radiation to penetrate into the ocean mixed layer. This increases the ice-ocean interfacial heat flux (Fig. 1c) and results in a larger amount of basal ablation $(0.36 \mathrm{~m})$ than is present in the baseline simulation $(0.19 \mathrm{~m})$.

The dominant process that affects the ice thickness during the non-summer months is basal accretion, which acts as a negative feedback. Because thin ice insulates the ocean less efficiently from the atmosphere, during the winter months more basal accretion occurs for the perturbed case $(1.34 \mathrm{~m})$ as compared to the baseline simulation $(0.99 \mathrm{~m})$. This essentially acts to thicken the ice cover. Thus, the resulting ice-thickness balance obtained by the model is one with a thinner ice cover that undergoes a larger seasonal cycle.

The mean annual response of the different model simulations to warming perturbations is shown in Figure 2. The annual area-averaged ice thickness is shown in Figure 2a, and the system gain of the various feedback mechanisms is shown in Figure 2b. The four different model variations include a control run and simulations in which the albedo, ocean, and combined albedo-ocean feedbacks are inoperative. Each model was run for LW perturbations of 5, 10, 15, 20 and $25 \mathrm{~W} \mathrm{~m}^{-2}$. Thus, a matrix of $4 \times 5$ experiments was obtained. The combined albedo- ocean feedback is responsible for a large fraction of the total sensitivity of the ice thickness, with values of gain over 0.5 for relatively small LW perturbations. The individual albedo and ocean feedbacks
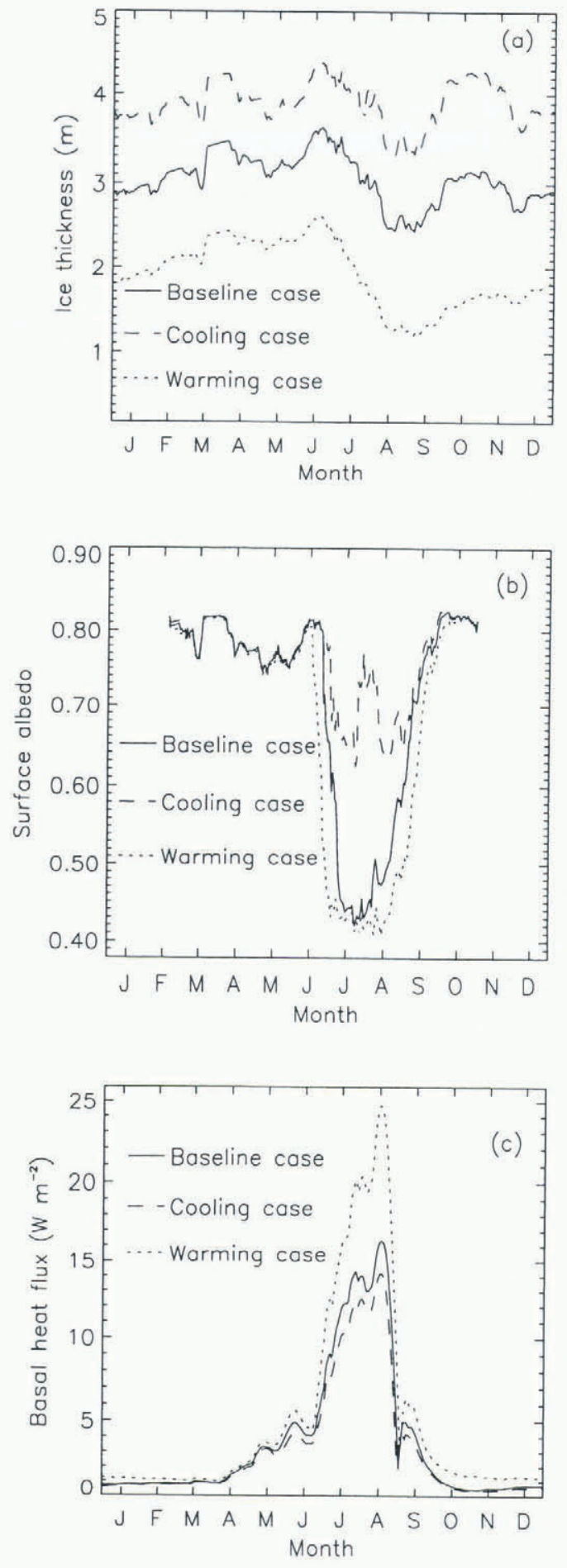

Fig. 1. The annual cycle of (a) ice thickness, (b) surface albedo, and (c) basal heat flux in response to a symmetric $10 \mathrm{~W} \mathrm{~m}^{-2}$ warming and cooling perturbation. The baseline simulation results are also shown for reference.

have a similar importance for determining the annual average ice thickness. For essentially all of the LW perturbations examined, the combined feedback gain is not equal to the sum of the two individual feedback gains. Thus, the albedo and ocean feedbacks are not independent. The albedo feedback largely affects processes at the surface of the ice. However, by lowering the total surface albedo and causing thinner ice to occur, more solar radiation penetrates into the ocean mixed layer. This activates one of the primary positive ice-ocean feedbacks by increasing basal ablation rates and resulting in thinner ice. Thus, there is some "overlap" between the ocean and albedo feedbacks that causes the 

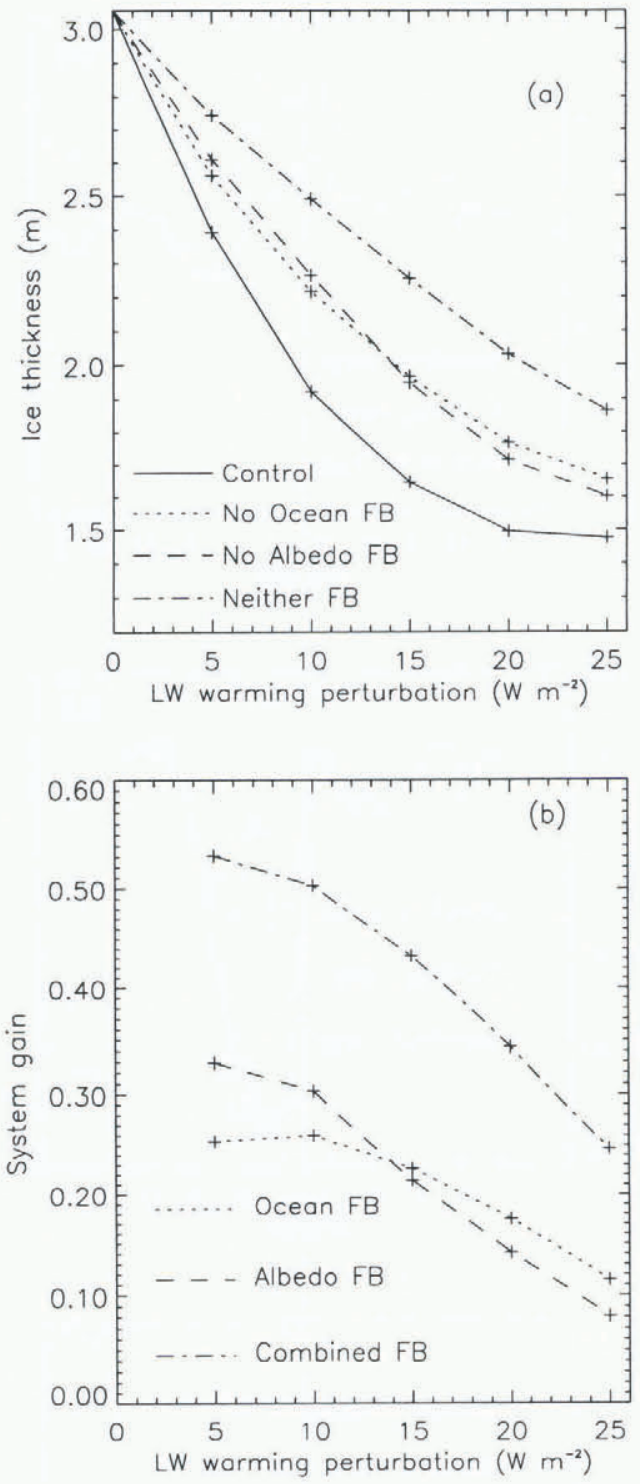

Fig. 2. The model response to $L W$ warming perturbations. (a) The response of the annual area-average ice thickness for the control run and cases that exclude ocean feedbacks, albedo feedbacks and combined ocean - albedo feedbacks. ( $b$ ) The system gain of the different feedback mechanisms.

sum of the gains of the individual feedbacks to be larger than the gain of the combined feedback. This occurs for relatively small LW perturbations.

For larger LW heat flux perturbations, the combined feedback system gain is larger that the sum of the individual gains. This is caused by an additional feedback that occurs during the non-summer months as the ice thins. As mentioned above, basal accretion rates are larger for thinner ice. This is a non-linear relationship, and as the ice becomes thinner the negative feedback mechanism associated with larger basal accretion becomes stronger. This mechanism acts to stabilize the ice-cover response to a heat flux perturbation and results in a general decrease in the feedback gain with increasing LW heat flux perturbation.

\section{Cooling perturbations}

The response of the model to a $10 \mathrm{~W} \mathrm{~m}^{-2}$ cooling perturbation is also presented in Figure 1. Similar mechanisms are active in both the cooling and warming perturbation scenarios. The surface albedo (Fig. lb) is significantly higher in the cooling perturbation simulation due to the presence of year-round snow cover on most of the ice categories. The lead fraction still increases during the summer months due to dynamic processes, and this accounts for the small decrease in albedo during this time. Because the ice is largely snow covered throughout the year, surface iceablation processes have a negligible effect on the ice thickness. Changes in the summertime basal heat flux (Fig. lc) as compared to the baseline simulation are largely due to the decrease in solar radiation that penetrates through the ice and leads into the ocean mixed layer. This results in a smaller amount of basal ablation. As in the case of a warming perturbation, ice-accretion rates differ due to the thickness of the ice cover. This results in $0.20 \mathrm{~m}$ less basal accretion in the $10 \mathrm{~W} \mathrm{~m}^{-2}$ cooling perturbation case.

The annually area-averaged ice thickness as a function of a cooling LW flux perturbation, and the gain of the different feedback mechanisms that are examined, are presented in Figures 3a-b. The experiments shown here are analogous to the warming perturbation experiments. As the cooling
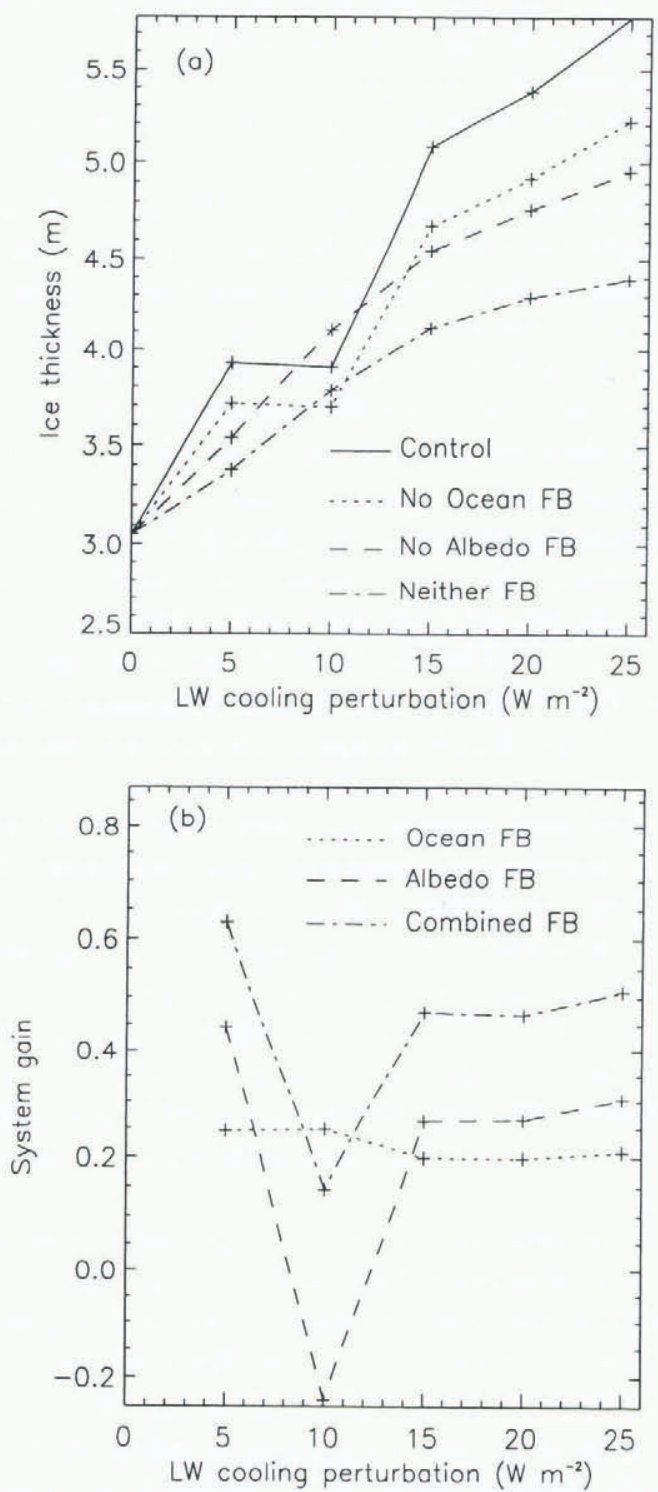

Fig. 3. The model response to LW cooling perturbations. (a) The response of the annual area-average ice thickness for the control run and cases that exclude ocean feedbacks, albedo feedbacks and combined ocean-albedo feedbacks. (b) The system gain of the different feedback mechanisms. 
perturbation increases, the length of the melt season decreases until the ice remains snow covered year round. Before the ice reaches this year-round snow-covered state, changes in the surface albedo cause large changes in the amount of surface ablation that occurs. However, after reaching this state, surface ablation processes no longer directly effect the ice thickness. This causes changes in the surface albedo to directly affect the thickness of the snow cover as opposed to the ice cover. Thus, additional processes that are related to snow-ice interactions become important for determining the sea-ice thickness.

Because of these additional processes, neglecting the albedo feedback causes a very different ice-thickness response to surface heat-flux perturbations. This results in system gain values that vary substantially with changes in the LW cooling perturbation. In fact, for a $10 \mathrm{~W} \mathrm{~m}^{2}$ cooling perturbation, the albedo feedback actually acts to decrease changes in the ice thickness, resulting in a negative system gain value. For the cooling perturbations considered here, three different regimes occur in which different processes dominate in determining the ice thickness.

For LW cooling perturbations less than approximately $8 \mathrm{~W} \mathrm{~m}^{-2}$, a "surface ablation regime" is present. In this regime, the albedo feedback directly affects the ice thickness through the process of surface ablation. Thus, significant differences occur in the surface ablation when the albedo feedback is excluded. This dominates the ice-thickness response to the cooling perturbations. Snow-ice interactions are not largely affected by the albedo feedback mechanism within this regime.

A "transition regime" occurs for LW cooling perturbations between approximately 7 and $15 \mathrm{~W} \mathrm{~m}^{-2}$. In this regime, the albedo feedback has a reduced effect on surface ablation. This is due to the presence of year-round snow cover on many of the ice categories in all four simulations. The inclusion of the albedo feedback allows much thicker snow cover to result and this causes snow-ice interactions to become important. Snow cover has two different properties that act to modify the ice thickness. It insulates the ice, resulting in smaller basal-accretion rates and thinner ice, and its weight can push the snow-ice interface below the water line, resulting in saturated snow cover that turns into ice and thickens the ice cover. These two effects are in competition. If the insulating effect dominates, the presence of the albedo feedback will actually cause a thinner ice cover to result. This is the case for the $10 \mathrm{~W} \mathrm{~m}^{-2}$ cooling perturbation simulation for which a negative system-gain value occurs.

The third regime occurs for LW cooling perturbations greater than approximately $15 \mathrm{~W} \mathrm{~m}^{-2}$. In this regime, the albedo feedback has no direct effect on the ice thickness because all categories are snow covered throughout the year. The albedo feedback causes larger snow thicknesses to occur, and thus the basal accretion is smaller (by approximately $0.15 \mathrm{~m}$ ) with the inclusion of this feedback. The presence of very large snow thicknesses also causes the saturation of snow to occur. This is a dominant process for determining the ice thickness when albedo feedbacks are included, resulting in approximately $0.30 \mathrm{~m}$ of ice growth. In the absence of albedo feedbacks, this process is negligible. The albedo and ocean feedbacks are independent in this regime since the sum of the two individual feedback gains is equal to the combined feedback gain. Although the albedo feedback affects the amount of solar radiation that is absorbed by the ice ocean system, the ice and snow covers are so thick that very little of this radiation is transmitted into the ocean. This essentially decouples the albedo and ocean feedback mechanisms.

In contrast to the albedo feedback, ocean feedbacks do not directly affect processes occurring at the ice surface. This allows similar snow covers to result regardless of the inclusion of ocean feedbacks. Thus, although the ice is relatively thinner when ocean feedbacks are excluded, the ice thickness follows a similar pattern to that of the control simulation. This results in relatively constant ocean feedback system gains.

\section{DISCUSSION AND CONCLUSIONS}

The sensitivity of sea-ice thickness to surface heat flux perturbations is significantly altered by the inclusion of the icealbedo and ice-ocean feedbacks. This is true for both warming and cooling perturbations. In general, the albedo and ocean feedbacks are not mutually exclusive. A warming perturbation causes a longer melt season and a larger lead fraction to occur. This decreases the surface albedo, leads to further increases in the surface melting, and acts as a positive feedback. It also allows more solar radiation to penetrate into the ocean mixed layer; therefore feedbacks associated with ice-ocean interactions are affected. The ocean mixed-layer temperature increases, causing more basal ablation to occur and enhancing the initial decrease in ice thickness. Thus, the ocean and albedo feedbacks interact with one another. This is generally true for both warming and cooling perturbation scenarios. However, for large cooling perturbation cases, the two feedbacks become decoupled due to the large ice and snow thicknesses that are present. The inclusion of both albedo and ocean feedback mechanisms is important in order to model realistically the sea-ice sensitivity to a surface heat flux perturbation.

For large warming perturbations, an additional negative feedback associated with basal accretion during the nonsummer months appears to be important. Because thin ice insulates the ocean less efficiently from the atmosphere, more basal accretion occurs under thin ice cover. This relationship is non-linear, and as the ice cover becomes substantially thinner this feedback becomes more important. If an interactive atmosphere were included, the importance of the basal accretion feedback would be likely to be reduced because warmer atmospheric temperatures would occur.

Additional feedback processes also occur under the influence of large cooling perturbations. After the ice becomes snow covered year round, the surface albedo feedback becomes less important for determining the change in ice thickness. However, additional processes occur that affect the sea-ice thickness, such as the insulating effects of snow cover and the saturation of snow cover on the ice surface.

An interactive atmosphere is undoubtedly a crucial component for the accurate determination of the climate response to heat flux perturbations. This study has focused on the sensitivity of the sea-ice cover to these perturbations and, in doing so, has not considered feedbacks that would occur with an interactive atmosphere. Future efforts will include the coupling of a single-column atmospheric model to our current ice-ocean model, and the investigation of feedback processes in the context of the atmosphere-sea-iceocean system. 


\section{ACKNOWLEDGEMENTS}

We would like to thank D. Bailey and D. Perovich for their helpful comments on the text. This research was supported by NSF OPP 9504261.

\section{REFERENGES}

Bourke, R. H. and R. P. Garrett. 1987. Sea ice thickness distribution in the Arctic Ocean. Cold Reg. Sci. Technol., 13 (3), 259-280.

Chapman, W. L. and J. E. Walsh. 1993. Recent variations of sea ice and air temperature in high latitudes. Bull. Am. Meteorol. Soc., 74 (1), 33-47.

Colony, R. 1978. Daily rate of strain of the AIDJEX manned triangle. AIDJEX Bull. 39, 85-110.

Curry, J. A., J. L. Schramm and E. E. Ebert. 1993. Impact of clouds on the surface radiation balance of the Arctic Ocean. Meteorol. Atmos. Phys., $51(3-4), 197-217$.

Curry, J. A., J. L. Schramm and E. E. Ebert. 1995. Sea ice albedo climate feedback mechanism. F. Climate, 8 (2), $240-247$.

Ebert, E. E. and J. A. Curry. 1993. An intermediate one-dimensional thermodynamic sea ice model for investigating ice-atmosphere interactions. 7. Geophys. Res., 98 (C6), 10,085-10,109.

Ebert, E. E., J. L. Schramm and J. A. Curry. 1995. Disposition of solar radiation in sea ice and the upper ocean. J. Geophys. Res., 100 (C8), 15,965 $15,996$.

Gaspar, P. 1988. Modelling the seasonal cycle of the upper ocean. 7. Phys. Oceanogr., 18 (2), 161-180.

Hansen, J. and 7 others. 1984. Climate sensitivity: analysis of feedback mechanisms. In Hansen, J. E. and T. Takahashi, eds. Climate processes and climate sensitivity. Washington, DC, American Geophysical Union, 130-
163. Geophysical Monograph 29, Maurice Ewing Series 5.

Hibler, W. D., III. 1980. Modeling a variable thickness sea ice cover. Mon. Wealher Rev., 108 (12), 1943-1973.

Holland, M. M., J. A. Curry and J. L. Schramm. In press. Modeling the thermodynamics of a distribution of sea ice thicknesses. Part II. Sea ice/ocean interactions. J. Geophys. Res..

Houghton, J. T., G. J. Jenkins and J. J. Ephraums, eds. 1990. Climate change: the IPCC scientific assessment. Cambridge, etc., Cambridge University Press.

Ingram, W. J., C. A. Wilson and J. F. B. Mitchell. 1989. Modeling climate change: an assessment of sea ice and surface albedo feedbacks. J. Geophys. Res., 94(D6), 8609-8622.

Kahl, J. D., D. J. Charlevoix, N. A. Zaitseva, R. C. Schnell and M. C. Serreze. 1993. Absence of evidence for greenhouse warming over the Arctic Ocean in the past 40 years. Nature, 361 (6410), 335-337.

Maykut, G. A. 1982. Large-scale heat exchange and ice production in the central Arctic. f. Geophys. Res., 87 (C10), 7971-7984.

Maykut, G. A. and M. G. McPhee. 1995. Solar heating of the Arctic mixed layer. 7. Geophys. Res., 100 (C12), 24,691-24,703.

Ramanathan, V. and 6 others. 1989. Cloud-radiative forcing and climate: results from the Earth Radiation Budget Experiment. Science, 243 (4887), 57-63.

Rind, D., R. Healy, C. Parkinson and D. Martinson. 1995. The role of sea ice in $2 \times \mathrm{CO}_{2}$ climate model sensitivity. Part $\mathrm{I}$ : The total influence of seaice thickness and extent. f. Climate, 8 (3), 449-463.

Rothrock, D. A. 1975. The energetics of the plastic deformation of pack ice by ridging. F. Geophys. Res., 80 (33), 4514-4519.

Schramm, J. L., M. M. Holland and J. A. Curry. In press. Modeling the thermodynamics of a distribution of sea ice thicknesses. Part I. Model description and validation. 7. Geophys. Res..

Thorndike, A. S., D. A. Rothrock, G. A. Maykut and R. Colony. 1975. The thickness distribution of sea ice. f. Geophys. Res., 80 (33), 4501-4513.

Weatherly, J.W. 1996. Greenhouse warming in an Arctic sea ice ocean model. [Abstract.] EOS, 77 (3), Ocean Sciences Meeting Supplement, OS107. 